could be due to spatial responses to particular forcings and/or to internal variability. He also argued that data assimilation of paleo-proxy data in models could improve our understanding of past changes.

\section{Theme 4-Rapid hydrological change}

Dirk Verschuren (Gent, Belgium), using proxy evidence from Europe and Africa, argued that a number of periods of cooler and wetter conditions, inferred from peatland and lake-level changes in Europe, corresponded to periods of reduced solar activity. In Africa, especially in Eastern Equatorial Africa, there was some evidence for a similar inverse relationship between solar activity and moisture.

Martin Claussen (Hamburg, Germany) argued that rapid climate change, capable of affecting early civilizations, occurred in North Af- rica during the Holocene, and that the climate at 5500 BP was especially unstable. He maintained that Earth system models are now capable of simulating rapid swings between arid and wet phases in the past but may not yet be able to predict future rapid transitions reliably.

In the final keynote, Ray Bradley (Amherst, USA) presented an array of evidence to demonstrate the relevance of understanding past climate to provide insights for the future. He stressed the importance of understanding the cause and consequences of rapid changes, especially abrupt, unprecedented and persistent climate anomalies (AUPs), for which there were many examples, mainly droughts, in the paleo-record.

The meeting was attended by 250 people from 30 countries, including 83 students, 18 of whom received support. There were 150 posters covering the four themes, and book prizes were awarded to the five best student posters: Rixt de Jong (Lund, Sweden, Jun Inoue (Osaka, Japan), Bettina Stefanini (Dublin, Ireland), Auriel Per oiu (Romania), and Peter De Geest (Brussels, Belgium).

\section{FURTHER INFORMATION}

The HOLIVAR2006 website (www.holivar2006.org) will remain active for at least 12 months and is being updated with poster pdfs. It will also provide video-streaming of the keynote presentations. The official journal for papers is Climate of the Past, and the conference book (Global warming and natural variability: a Holocene perspective, Eds. Battarbee, R.W. and Binney, H.) will be published by Blackwell in 2007.

Rick Battarbee, Heather Binney and Mike HUGHES

Environmental Change Research Centre, University College London, UK: r.battarbee@ucl.ac.uk

\title{
PAGES/CLIVAR workshop on past millennia climate variability - synthesis and outlook
}

Wengen, SWitzerLand; 7-10 June 2006

This workshop followed the spirit of the reorganized PAGES/CLIVAR working group (see PAGES News, 2005/1). It was organized by the PAGES/CLIVAR Intersection Working Group (P. Jones, M. Mann, H. Wanner, K. Briffa) in concert with the PAGES office in Bern. Twenty-four participants (Fig. 1), representing various different climate data and modeling sub-disciplines were invited to discuss the state of the art and future needs in the study of late Holocene climate variability. Two days were devoted to short presentations and extended discussions on hot topics and issues, covering the areas of proxy data, climate reconstructions and paleoclimate modeling. The issue of how to deal with uncertainties in assessing climate variability over the past one-to-two millennia was discussed in detail. Questions posed and addressed included: What do current uncertainty estimates take into account? How relevant are current uncertainties for the general findings regarding past climate variability in the past? The following primary conclusions were reached:
- Late 20th century warming is likely anomalous in the context of the past 1000 years at hemispheric scales. There is evidence for periods of cooling and warming that occur on all timescales and on all spatial scales. For pre-instrumental periods, it is vital to consider both the spatial extent and duration of regional climate anomalies.

- Comparisons of model-predicted and reconstructed climate variations over the past several centuries are generally favorable, taking into account the currently available data and their uncertainties.

- Natural radiative forcing appears to play an important role on the relevant timescales. Solar forcing may account for variability on decadal through millennial timescales. Individual volcanic eruptions impact climate generally for only a few years but longer-term episodes of closely spaced large eruptions (e.g. as in the early 19th century) can lead to multidecadal-scale effects.

- Usefully constraining estimates of global climate sensitivity from paleoclimate data will require a better knowledge of past radiative forcing and the amplitude of internal, as well as forced, natural variability.

The discussions emphasized the importance of distinguishing past hemispheric or global-scale variability from regional variations. For example, it was shown that the widely used term "Medieval Warm Period" is simply not an appropriate description of Medieval climate in many regions of the world. Coral data from Kim Cobb, for example, suggest instead a "Medieval Cool Period" for the tropical Pacific. Such considerations reinforce the principle that a better regional documentation of past climate is necessary to better understand the past. The group that was assembled took note of the importance of focusing not simply on the often emphasized hemispheric mean temperature variations of past centuries, but also on spatial 


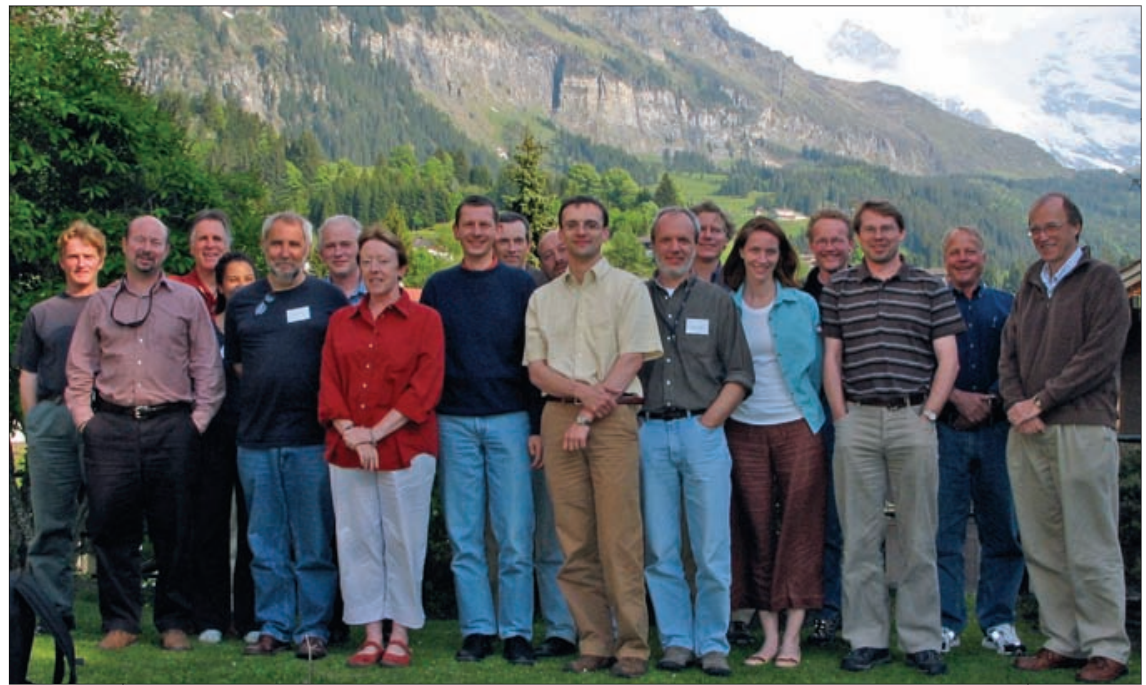

Figure 1: The group of participants in front of the Wengen mountains.

patterns of surface temperature, atmospheric circulation, precipitation and drought. The group also noted the importance of considering dynamical mechanisms such as the El Niño/Southern Oscillation (ENSO) in interpreting past climate changes. The recent PAGES and CLIVAR initiatives on past regional variability in South America and the Mediterranean region follow this principle (see PAGES News 2005/1, 2005/2 and 2005/3).

The group recognized that additional effort is needed in the archiving of paleoclimate data and associated metadata. They also agreed on the importance of encouraging scientists to provide not just the proxy data and climate reconstructions, but as much information as possible about random and systematic error and uncertainty. The latter information is crucial, for example, in comparisons of paleoclimate evidence with model simulation results. The participants agreed that progress in climate modeling approaches is also crucial to a better understanding of past climate variability, and to the assessment of current and future anthropogenic impacts on climate. To this end, the workshop participants agreed to plan a community-wide "paleoclimate re- construction challenge" in the near future (see Program News, page xx, this issue). This challenge will build on the theme of model intercomparison, using synthetically derived "pseudoproxy" test datasets derived from climate models as a test of methods used in paleoclimate reconstruction, similar in many respects to last year's "EPICA Challenge" initiative (see e.g. EOS, No. 38, 2005). A second project addressing proxy data uncertainties and data archiving is also being planned.

The four-day workshop in the unique setting of the snow-covered Bernese Alps provided a stimulating setting for informal discussions, setting the stage for productive activities in the months and years ahead. A synthesis publication on the state of the art of late Holocene climate variability will be published by the workshop participants. Follow-up activities are currently being planned.

\section{ACKNOWLEDGEMENTS}

The workshop was funded by the Electric Power Research Institute (EPRI), PAGES,

Swiss NCCR-Climate and CLIVAR.

Christoph Kull ${ }^{1}$, Keith Briffa, Phil Jones, Michael Mann and Heinz Wanner 'PAGES Office, Bern, Switzerland kull@pages.unibe.ch

\section{ICDP workshop PASAD0: Deep drilling at Laguna Potrok Aike, a maar lake in southern Argentina}

Río Gallegos, Argentina; 15-19 March 2006

Patagonia is subjected to shifts in polar and mid-latitude winds, pressure fields and precipitation regimes, as well as to variations related to $\mathrm{EI} \mathrm{Ni-}$ ño Southern Oscillation (ENSO) and the Antarctic Oscillation (AO). Therefore, environmental and climatic reconstructions have the potential to provide unique records of variations in the hydrological cycle, changes in aeolian dust deposition, and consequences and frequencies of volcanic activities. Since 2001, crater lakes of the Pali Aike Volcanic Field (southernmost Patagonia, Argentina) have been studied in the framework of the interdisciplinary project "South American Lake Sediment Archives and Modelling" (SALSA) funded by the German Climate Research Program (DEKLIM) and carried out in close cooperation with Argentine scientists (PAGES News 12/2, 9-11). On-site monitoring and multidisciplinary reconstructions based on sediment cores from the maar lake Laguna Potrok Aike have formed the basis for environmental and climatic reconstructions on decadal up to millennial time scales. Located $52^{\circ} \mathrm{S}$, the lake received dust and volcanic ash from Patagonia and the Andean volcanic chain, which are distributed not only across South America but also blown over the South Atlantic and onto Antarctica. Thus, isotopic and aerosol tracers could be used to link these different areas, making not only inter-site but also inter-archive correlations available. Such data will advance hemispheric reconstructions of climate variability and proxy-model comparisons to better understand climate forcing factors. First results are promising but coring ended around $16 \mathrm{cal} \mathrm{ka} \mathrm{BP}$, due to technical restrictions of the available coring device.

With additional funding from the Priority Programme "ICDP" of the German Research Foundation (DFG), it was possible to carry out deep seismic surveys, which revealed $>150 \mathrm{~m}$ of lacustrine sediments underlain by $>350$ $\mathrm{m}$ of volcano-clastic deposits. As the maar formation occurred at 